\title{
La elección lingüística en la moneda, ¿un marcador de identidades? Casos de incoherencia entre las leyendas monetarias y el registro epigráfico*
}

\section{The linguistic choice in coin legends, an identitary marker? Some case-studies of language inconsistency between coin legends and inscriptions}

\author{
María José Estarán Tolosa ${ }^{1}$ \\ Proyecto LatinNow (University of Nottingham / University of Oxford)
}

\section{RESUMEN}

En este artículo se analizan los criterios que llevaron a determinadas comunidades a grabar sus leyendas monetarias en una lengua diferente de la que registra la epigrafía coetánea, y se valora en qué casos esta elección lingüística responde a la necesidad de una construcción de la identidad y en cuáles esta decisión se debe a otro tipo de causas, vinculadas estrechamente con el cambio lingüístico que se produjo a lo largo de los dos últimos siglos a. C. y el primero d. C. en el occidente mediterráneo.

\section{SUMMARY}

This paper explores the reasons why the language of the coin legends issued by certain communities is different from the language attested in the epigraphic record, distinguishing those cases where the linguistic choice was the result of the need of constructing a civic identity from those where this decision was due to other kind of causes, narrowly linked to the linguistic shift that was currently happening in the Western Mediterranean when these coins were produced ( 2 nd cent. $\mathrm{BC}-1$ st cent. AD).

PALABRAS CLAVE: elección lingüística; cambio lingüístico; identidad cívica; latinización; numismática; epigrafía; occidente mediterráneo antiguo.

\footnotetext{
Este artículo es la versión ampliada de una comunicación presentada en el XV Congreso Internacional de Epigrafía Griega y Latina (Viena, agosto-septiembre de 2017). Se ha realizado gracias a la financiación de la Individual Fellowship Marie Sklodowska-Curie ARD-West (H2020-MSCA-IF-2014-654731, Université libre de Bruxelles) y del proyecto ERC LatinNow (ERC-2016-STG 715626, University of Nottingham).

2 mjestaran@gmail.com/ ORCID iD: https://orcid.org/00000002-9650-7652
}

KEY WORDS: linguistic choice; linguistic shift; civic identity; Latinization; numismatics; epigraphy; Ancient Western Mediterranean.

COMO CITAR ESTE ARTÍCULO / CITATION: Estarán Tolosa, M. J. 2019: "La elección lingüística en la moneda, ¿un marcador de identidades? Casos de incoherencia entre las leyendas monetarias y el registro epigráfico", Archivo Español de Arqueología 92, 173-189. https://doi. org/10.3989/aespa.092.019.009

Las leyendas monetarias aportan una información preciosa sobre las circunstancias sociopolíticas de la ceca en el momento en el que la moneda era acuñada; información que no sólo se desprende de su contenido sino también de la lengua en la que estas se redactaban. Ningún elemento de la moneda, incluida la lengua de sus epígrafes, es fruto de un acto irreflexivo, pues se trata de documentos oficiales. Son, en realidad, propaganda del discurso oficial de las ciudades o de las comunidades acuñadoras, "the surface expression of the dominant cultural system" (Swain 1996: 8; cf. también García-Bellido 1993: 337; Metcalf 1999: 15; Howgego 2005: 16; Chaves 2009: 318-319). Las monedas, en tanto que documentos representativos de una colectividad, exhiben elementos simbólicos de ella. Sin embargo, esta selección de elementos no necesariamente coincidía con la realidad: en ocasiones, la (s)elección lingüística de las inscripciones monetarias no era coherente con la lengua más utilizada por la comunidad, o al menos, con la lengua que tenemos documentada en la epigrafía (especialmente en la de tipo privado) o la que se comenta en las fuentes literarias grecolatinas.

Copyright: () 2019 CSIC. Este es un artículo de acceso abierto distribuido bajo los términos de una licencia de uso y distribución Creative Commons Reconocimiento 4.0 Internacional (CC-by 4.0). 
En el presente artículo se exponen algunos ejemplos de esta aparentemente contradictoria elección lingüística con el fin de ilustrar las diferentes situaciones en las que se dio este fenómeno. Estos estudios de caso están extraídos de comunidades cívicas seleccionadas del occidente mediterráneo (península itálica, Sicilia y, sobre todo la península ibérica) mayoritariamente (aunque también se tratarán algunos significativos casos orientales) y datables entre los siglos III a. C. y I d. C. El trabajo está estructurado en dos grandes apartados, correspondientes a dos situaciones sociolingüísticas determinadas por las que se pudo dar esta particular elección lingüística: 1) La recuperación de una lengua (o de un sistema de escritura) caída en desuso (o que incluso nunca antes se había utilizado), diferente de la documentada por el registro epigráfico, con el fin de construir una identidad cívica. Esto ocurrió de manera muy excepcional en algunas situaciones de evidente alteridad, como las bélicas, o con el fin de evocar un pasado mítico. 2) La incoherencia entre la lengua de las monedas (en latín) y la del registro epigráfico (en la lengua vernácula correspondiente) que refleja el bilingüismo social resultante de la dominación romana de los territorios occidentales. El estudio de este fenómeno está dividido en tres fases correspondientes a la progresiva presión sociocultural ejercida desde Roma.

Pese a que esta incoherencia entre la lengua elegida para los rótulos monetarios y la de los conjuntos epigráficos de un mismo lugar no es un asunto desconocido, no son escasas las explicaciones para la elección lingüística en la moneda como expresiones de una identidad cívica o étnica, para lo que con frecuencia se aduce una conocida frase de The Roman Near East, de F. Millar (1993: 257), "The most explicit symbols of a city's identity and status were its coins". Sin embargo, no tantas veces se reproduce la frase siguiente, de la que el presente trabajo es deudor: "But behind this statement lies a multitude of problems". Por ello, en las próximas páginas se estudiarán los criterios de elección lingüística de los epígrafes monetarios, y se analizará particularmente el efecto de la expansión romana y de la latinización en el cambio lingüístico que queda reflejado en el registro numismático.

Como se ha dicho, a la hora de explicar una elección lingüística en la moneda, habitualmente se recurre a la capacidad simbólica de la lengua, es decir, se identifica una determinada lengua o un sistema de escritura con una comunidad dada, en el mismo sentido en el que Grosjean hablaba de la lengua como "an emblem of group membership and solidarity" (1982: 117). Este razonamiento en virtud del cual la identidad lingüística y la étnica están estrechamente unidas es en gran medida heredero de postulados nacionalistas decimonónicos y, como quedará patente en las próxi- mas líneas, en ocasiones no se ajusta a la realidad del mundo antiguo ya que de él se deriva la existencia de un sentimiento de identidad comunitaria, étnica, fundamentado en el uso de una lengua común (Bourdin 2012: 51-56, Wulff 2009, 2011). Por esta razón es por la que la documentación numismática no puede ser interpretada como un indicador de las identidades étnicas "en bruto" (Williamson 2005: 19).

Esta interpretación de la lengua, y en particular, de la lengua de los rótulos monetarios, como expresión de una identidad colectiva, que puede ser válida para determinadas situaciones, también puede llevar ocasionalmente a la comisión de anacronismos. Concretamente, en el caso de los trabajos sobre la dominación romana y la latinización, se tiende a ver una suerte de reticencia o de resistencia ideológica de los territorios conquistados a hablar y escribir en latín cuando cada vez hay más argumentos para pensar que la política lingüística de Roma, de haber existido, habría sido verdaderamente abierta y que, de hecho, el dominio del latín no era un requisito necesario para ser ciudadano romano. Estas explicaciones, en virtud de las cuales se razona una determinada elección lingüística mediante una simple dialéctica de dominación y resistencia (Bénabou 1976$)^{3}$, tienden a simplificar nuestra percepción de la actitud lingüística de ambos grupos de hablantes. Es preferible huir de estas posturas esencialistas a la hora de hablar de identidades lingüísticas en la Antigüedad: la existencia de un sentimiento de identidad colectiva canalizada gracias al uso de una lengua común no es en absoluto descartable; pero tampoco debería emplearse como explicación más inmediata de la elección lingüística de cualquier texto. De hecho, incluso en la actualidad el dominio de una lengua no es un requisito imprescindible de pertenencia a determinado grupo étnico: la etnicidad está mucho más relacionada con el simbolismo de una lengua que con su uso real por parte de los miembros de un grupo (Hamers y Blanc 2000: 277). Veamos cuánto puede aportar el estudio comparado de las inscripciones y los rótulos monetarios al análisis de esta cuestión. En el mapa (Fig. 1) el lector encontrará la ubicación de las principales cecas mencionadas a lo largo de este trabajo.

$$
* * *
$$

A partir de los siglos IV/III a. C. el Mediterráneo asistió a una compleja situación política que desenca-

3 El término "resistencia", que también sirvió a Mastino (1985: 48) para el estudio del caso sardo y a Häussler (2002) para el norte de Italia y las Galias. Van Dommelen (2001: esp. 44,2007 ) ha reelaborado este concepto, desproveyéndolo de una dicotomía tan marcada "conquistador / conquistado", como "silent resistance". Sobre él, v. Häussler 2013: 22-23. 


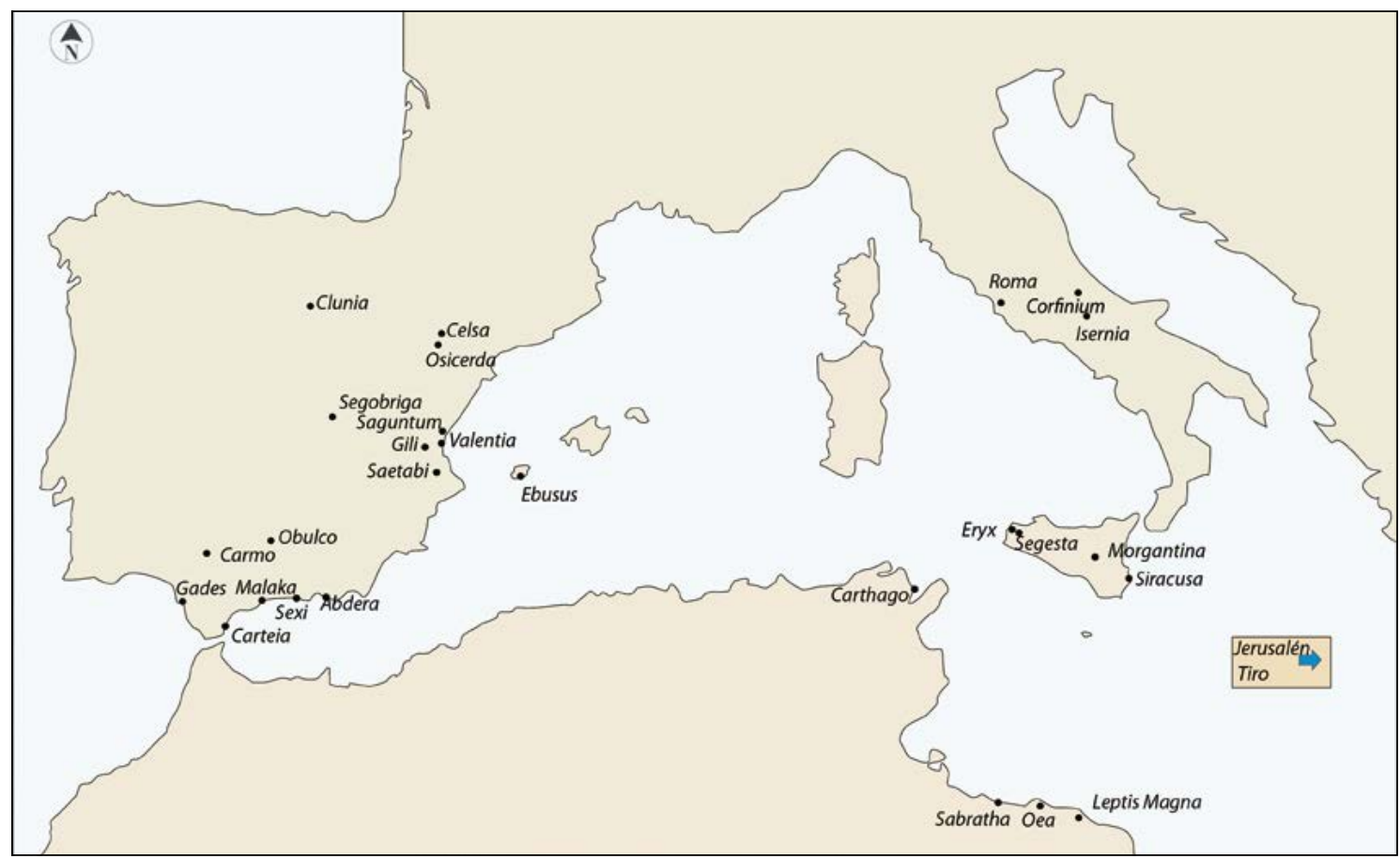

Figura 1. Mapa de ubicación de las cecas que se mencionan a lo largo de este artículo (elaboración propia).

denó largos episodios bélicos, durante los cuales la economía monetaria se generalizó en los territorios occidentales; y también se incrementó el tráfico de personas, mercancías y técnicas. Las lenguas y los sistemas de escritura de las potencias hegemónicas, el griego, el púnico y el latín, entraron en el acervo cultural de los pueblos circunmediterráneos y de sus elites, que, a su vez, impulsaron la fabricación de moneda cívica con leyendas que se adecuaban a sus necesidades. Especialmente a partir de la derrota de Cartago en 241 a. C., tras la cual Roma tomó el control de Sicilia, el latín fue la lengua de una gran potencia militar en crecimiento; una potencia que, pese a sus aspiraciones imperiales, carecía de programa alguno de política lingüística (Dubuisson 1983; Adams 2003: 425, 562, 758; Rochette y Clackson 2011). La idea de un imperio multilingüe no suponía ningún conflicto para la identidad ni para la administración de la capital del Lacio.

Como consecuencia de la expansión de Roma, durante los siguientes dos siglos y medio asistimos en el occidente mediterráneo a un proceso histórico de reelaboración de identidades colectivas, y, a la vez, de introducción de una lengua colonial en un puesto de superioridad política, económica y administrativa, es decir, de la creación de situaciones generalizadas de bilingüismo social ${ }^{4}$. En este contexto sociolingüístico

\footnotetext{
4 Sobre el bilinguismo social ("societal bilingualism"), véase Mullen 2012: 23-29 y Fishman 2014. Se trata del uso de dos
}

lenguas dentro de la misma comunidad, elegidas en función del amplio rango de factores que puedan afectar a esta colectividad, a los que Fishman 1965 denominó "dominios". Este bilingüismo social, si es inestable, puede desembocar en un cambio lingüístico, en último término.

La diglosia es un tipo de bilingüismo social en el que las funciones para las que se elige cada lengua están muy separadas y sus límites de uso están muy claros (una de ellas tiene mayor estatus, H(igh); la otra, menor, L(ow)) (Ferguson 1959), lo que da lugar a una descripción demasiado dicotómica de la situación sociolingüística que puede dar problemas si no se cuenta con una muestra muy amplia de datos, como es el caso de cualquier conjunto epigráfico, donde los textos sólo dan una visión parcial de la realidad y no conocemos lo que pudo pasar en todos los dominios linguísticos. La "diglosia amplia" de Fishman (1967) es más flexible que la de Ferguson y podría encajar mejor en la situación que buscamos definir; aunque ninguna de sus tres combinaciones de diglosia y bilingüismo (1967: 102) resulta plenamente satisfactoria. Sobre la aplicación de los conceptos "bilingüismo" y "diglosia" al contacto de lenguas fragmentariamente testimoniadas, cf. Langslow (2002: 26-28), quien toma la definición de diglosia de Ferguson (1959); no la revisión de Fishman (1967).

Adams y Swain (2002: 9-10) se muestran contrarios a la adecuación del término "diglosia" para la Antigüedad, al menos para el Mediterráneo oriental, donde, efectivamente, no parece que hubiera diglosia sino multilingüismo, así como una clara distinción funcional de las lenguas; cf. también Adams 2003: 538-541 (Egipto) y 754; y Lee 2012.

El multilingüismo oriental no existió en la región occidental del Imperio romano, donde no había tampoco una lengua equivalente al griego. Por eso, el latín adquirió rápidamente el papel de lengua de estatus superior (H(igh)) como lengua de la administración, del ejército, de la cultura y, en muchos casos, también como única lengua escrita y, en consecuencia, en ciertos contextos, podría hablarse de "diglosia". Es cierto que en la mayoría de las ocasiones no se trataría de una situación sociolingüística binaria, sino un escenario muy complejo y fluido. 
la autoridad no obligaba a hablar ni a escribir en latín; pero su uso estaba estrechamente relacionado con la obtención de una posición social cómoda o de un estatuto jurídico privilegiado. El resultado de la prolongación de esta situación de forma sostenida a lo largo del periodo republicano fue que las lenguas vernáculas del occidente mediterráneo (las lenguas itálicas, el etrusco, las lenguas paleohispánicas, el galo, entre otras) dejaron inexorablemente de escribirse, y, poco a poco, de hablarse. Como se señalará en el apartado correspondiente, la política de Augusto fue el gran punto de inflexión para el triunfo del latín como lengua epigráfica en el que se dio el golpe de gracia a los textos en lenguas locales.

\section{SITUACIONES DE ALTERIDAD Y ELECCIÓN DE UNA LENGUA "HISTÓRICA" O MÍTICA PARA LA CONSTRUCCIÓN DE UNA IDENTIDAD COLECTIVA}

Exploremos, en primer lugar, una elección lingüística derivada de situaciones excepcionales: cuando se seleccionó una lengua (o un sistema de escritura) en desuso, o que nunca había sido utilizada por la comunidad. Tenemos constancia de este rescate de la lengua "nacional" (empleo este término con todas las cauciones necesarias) en situaciones de conflicto político o bélico, en el mismo momento en el que este desencuentro está ocurriendo, por lo que se trata de emisiones puntuales acuñadas en circunstancias que implicaban cierta situación de alteridad. En estos casos puntuales, efectivamente, la elección lingüística sí está directamente vinculada con la construcción de una identidad colectiva, cívica o étnica (Melucci 1995: 48-49).

Uno de los ejemplos más conocidos de este fenómeno son las acuñaciones de las dos revueltas judías bajo Nerón y Adriano, cuyas leyendas, redactadas en lengua y escritura paleohebreas, en desuso desde hacía siglos, aluden al carácter sagrado y a la libertad de Jerusalén (Goodman 2005; Lykke 2012: 40-41; Deutsch 2012) (Fig. 2). Estas emisiones revisten particular interés porque en ellas se aprecia claramente cómo se construía una identidad cívica en oposición a otra, hostil. En su esclarecedora explicación, Goodman toma la pureza del contenido en plata de las emisiones de shekels y también la iconografía como una

Pese a ello, creo que este concepto puede resultar muy útil para describir las circunstancias sociolingüísticas de determinadas regiones en ciertos momentos iniciales de la conquista, donde el latín tenía claramente el papel de lengua $\mathrm{H}$ y las lenguas locales, el de lengua L. Lo ideal es que, si se aplica el concepto "diglosia" a nuestras reconstrucciones sociolingüísticas en la Antigüedad, se haga con la caución de que no puede hacerse con su versión más rígida (cf. Mullen 2012: 24-25). forma de romper con la moneda del opresor y hace una apreciación muy interesante según la cual la anonimidad de la autoridad emisora puede interpretarse como una reivindicación de la unidad nacional ${ }^{5}$.

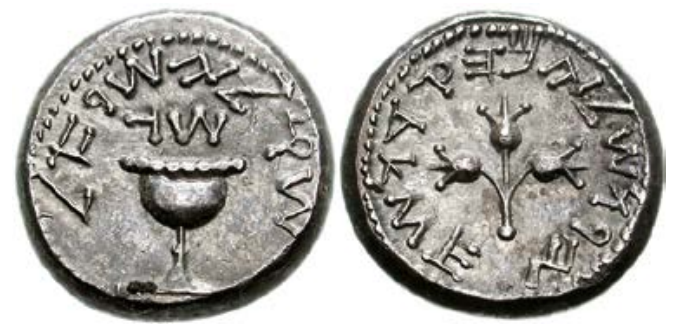

Figura 2. Medio shekel de la Primera Revuelta Judía, (22mm, 13.19 g, 12h). A: ŠQL YŠR'L ("Shekel de Israel"), R:

YRWŠLM QDŠH ("Jerusalén la santa"). Colección Semon Lipcer (www.cngcoins.com, 783951).

Estas piezas jerosolimitanas son el caso más conocido, pero no el único, del uso de una lengua "nacional" en desuso para representar a una comunidad. El numerario acuñado durante la Guerra de los Aliados por el bando itálico, enfrentado a Roma (Campana 1987; Burnett 1998; Rutter 2001: 55-57; Tataranni 2005; ImIt Italia 1 Coinage), es uno de los casos más precoces del uso de la moneda como propaganda política en favor de una causa concreta (Burnett 1998: 170; Adams 2003: 116, 757) (Fig. 3).
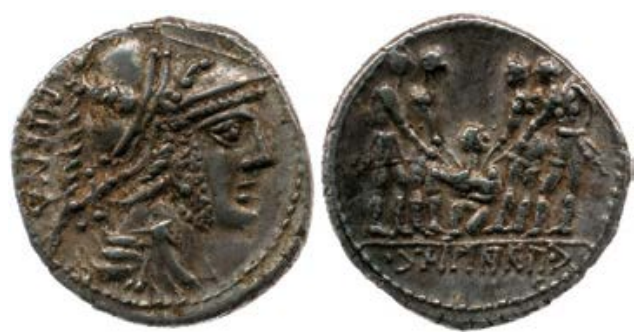

Figura 3. Bronce de la Guerra Social (Campana 83, 3.94g, $20 \mathrm{~mm}, 9$ h). A: viteliú R: C. Paapi. C. Roma Numismatics, e-Sale 22 (28/11/2015), lote 442 (https://www.acsearch.info/ search.html?id=2775688).

Algunas de estas monedas exhiben rótulos en osco, otras en latín, y otras son bilingües (Estarán 2016, O1). El alfabeto osco y el latino se usaron indistintamente para las marcas de control de estas emisiones (ImIt

\footnotetext{
5 Goodman (2005: 165) señala que las imágenes de estas emisiones rompen completamente con la línea de las anteriores. En ellas se pretende reflejar la santidad de la ciudad mediante imágenes de culto (cáliz, las granadas y la referencia al sukkot con citrones y palmas) cuya interpretación concreta, sin embargo, no está clara.
} 
Italia 1 Coinage, $\left.\mathrm{n}^{\circ} 407,408\right)$. Las leyendas en lengua y alfabeto osco consisten en los nombres y cargos de los comandantes de la causa itálica como C. Papius Mutilus (c. paapií c. mútil, Campana 1987, series $2 \mathrm{~b}$ y 5 ; mútil embratur, "traducción" al osco de "Mutilus imperator", Campana 1987, series 5 y 6a-b) y ni. luvki. $m r$. (Campana 1987, Serie 9a); y también en conceptos étnicos, como viteliú (Campana 1987, series 1, 4, 6c y 9a, 10), que significa "Italia", un término claramente alusivo a una identidad colectiva construida ad hoc durante este conflicto y que asimismo fue grabado en latín en otras emisiones (Campana 1987, serie 2b y 2014), o la leyenda de reverso de la serie 11, safinim, "Samnio" (cf. Scopacasa 2015: 30-41). Estos étnicos no pueden ser considerados como la alusión a la ceca (ImIt Italia 1 Coinage, Dart 2014: 116).

A primera vista, nada tiene de especial que se haya elegido la lengua local y la escritura nacional como representante de la identidad de los pueblos itálicos. De hecho, la iconografía de estas monedas tiene unos rasgos claramente militantes, especialmente la de los reversos, donde se encuentran escenas del juramento de los ocho pueblos itálicos contra Roma, ritos sacrificiales y también, la metáfora más explícita del conflicto: el toro itálico embistiendo a la loba capitolina (en los anversos se grabó una personificación de Italia, una cabeza femenina laureada o galeada que sustituía significativamente a la de Roma). Sin embargo, la elección de la lengua y el alfabeto "nacional" osco para estas monedas, es efectivamente muy relevante si pensamos que este sistema de escritura era ajeno a varios pueblos itálicos componentes del bando opositor a Roma, como los lucanos, que usaban el griego, y los pelignos, vestinos, marsos y marrucinos, cuyos textos más antiguos ya están escritos en alfabeto latino, con la excepción de las inscripciones en escritura sudpicena (ImIt Superaequum 1, 2; Interpromium (?) 1, A, B; Aufinium 1), muy anteriores a la Guerra Social.

Por otra parte, en Corfinio e Isernia, donde posiblemente se ubicaron los talleres de estas monedas, el alfabeto nacional no era la norma. De hecho, en Corfinio no se tiene documentado ningún texto en este sistema de escritura (ImIt, vol. 1: 261-299) y la misma ceca de Isernia ya acuñaba bronces en latín en 263-240 a. C., debido a la consecución de su estatuto colonial (ImIt Aesernia 1 Coinage), aunque en sus entornos sí se empleaba el alfabeto osco (v. Agnone, Pietrabbondante y Bovianum Vetus). En consecuencia, la revisión del material epigráfico revela que el alfabeto osco no era el sistema de escritura que utilizaba la mayor parte de pueblos representados en el numerario itálico, tampoco el de las ciudades donde estaban situadas las cecas. Y sin embargo, fue el alfabeto que se grabó en gran parte de las acuñaciones itálicas.
La expresión del sentimiento de unidad ante el otro no es la única razón por la cual se pudo elegir una lengua "histórica" en las emisiones monetarias. También está documentada en relación con la evocación del mito fundacional de la ciudad. Uno de los ejemplos más claros de esta práctica es la producción de Tiro bajo Gordiano III: un numerario trilingüe que representa cómo Dido funda Cartago, en una bella emisión con letreros en latín en el anverso, acompañando el retrato imperial; y didascalías en griego $(\Delta \varepsilon 1 \delta \omega v)$ y fenicio ('lt șr) en el reverso (BMC 409, Robinson 1999: 43; Howgego 2005: pl. 1.4 no. 41) ${ }^{6}$. La recuperación de una lengua representativa del pasado de la comunidad es perfectamente clara en unas emisiones coetáneas de la anterior (BMC 408 pl. 33.5; Robinson 1997 y 1999; Butcher 2003: 280, Hirt 2014: 11-12), en cuyos reversos se representó a Pigmalión, el hermano y enemigo de Dido. La didascalia alusiva a su nombre se grabó en caracteres fenicios, pgmljn, que era en realidad la transcripción de la versión griega de este nombre, Pygmalion, y no de la fenicia original, pmytn, lo que denuncia de forma clara la ignorancia de la lengua fenicia por parte de los abridores de cuño tirios en 238-244 d. C. (cf. Beltrán 2011a: 29-30).

Es muy probable que la evocación de una lengua relacionada con un mito fundacional esté documentada en Hispania al menos en una ocasión, en Sagunto. Las emisiones de esta ciudad habían sido bilingües en latín e ibérico desde el último tercio del siglo siglo II a. C., mientras que la epigrafía saguntina de época republicana está íntegramente escrita en lengua y escritura ibéricas (con la excepción de una inscripción bilingüe en ibérico y latín, cf. Estarán 2016, I8, y de una inscripción fragmentaria sobre un bloque de piedra de Montaña Frontera, cf. ELRH, C57), una interesantísima situación sociolinguiística sobre la que no puedo detenerme aquí (cf. Beltrán 2011a: 31-35; Estarán 2016, I3 e I8). En cualquier caso, contra todo pronóstico, la última emisión antes del periodo IV (40/30 - 37 d. C.) exhibe un rótulo en griego, SAG(OUNTON) POL(IS) (RPC 485. Ripollès y Llorens 2002, cat. 412415; Velaza 2002: 128-129, 144; Beltrán 2011a: 35; Amela 2012). Pese a que se han hallado algunas inscripciones en esta lengua en el territorio saguntino ${ }^{7}$,

\footnotetext{
${ }^{6}$ La iconografía de estas monedas muestra a Dido como fundadora de Cartago, un mito fundacional recurrente en la numismática tiria, cuestión sobre la que trata Hirt (2014).

7 Un carmen epigraphicum funerario, datable en los dos primeros siglos de nuestra Era, sin más precisiones, y algunos grafitos, son las únicas inscripciones saguntinas escritas en griego que se han hallado hasta la fecha. Otro conjunto de inscripciones saguntinas en griego proceden de fuera de la península ibérica: cuatro glandes de plomo, unas estampillas sobre ánforas grecoitálicas, y otras estampillas de origen y paradero desconocidos (Velaza 2002: 128-129 y De Hoz y
} 
su naturaleza y su cantidad no son suficientes para justificar la existencia de una comunidad de hablantes de griego en este importante núcleo urbano $\mathrm{y}$, por tanto, tampoco para hipotetizar que esta leyenda en griego representara a la comunidad helenófona de Sagunto. Se entiende, en consecuencia, que es una elección excepcional de la lengua griega que sirve para sustentar la construcción del mito fundacional de la ciudad a partir de los griegos venidos de Zakynthos (cf. Velaza 2002, nota 21 para el problema del mito fundacional). Por otra parte, cabe subrayar que también se usa un nuevo diseño monetario, como ocurrió en 130 a. C., que reutiliza los elementos anteriores (proa y victoria alada) y se basa en el anverso de los denarios augústeos de 32-29 a. C. conmemorativos de la victoria en Accio. La escasa calidad técnica de esta moneda con respecto de las emisiones anteriores también es llamativa (Llorens y Ripollès 2002: 108).

\section{ELECCIÓN LINGÜÍSTICA EN LOS RÓTULOS MONETARIOS DE COMUNIDADES BILINGÜES}

\section{Antes de la dominación romana. El caso de SiCILIA}

En los ejemplos precedentes la lengua y/o la escritura de los rótulos monetarios no coincide con la de las inscripciones y, pese a ello, fue elegida para representar a la comunidad. Sin embargo, como se expone en las próximas páginas, la razón habitual para la incoherencia entre la lengua de las monedas y la del registro epigráfico era que las elites se expresaran pública u oficialmente en la lengua $\mathrm{H}(\mathrm{igh})$ cuando la mayor parte de la comunidad hablaba una lengua L(ow) (ver nota 4). Esto podía ocurrir tras una sustitución repentina de las clases dominantes tradicionales por otras nuevas o, también, en circunstancias políticas estables en las que la lengua local no se utilizaba para los textos oficiales. Pensemos, por ejemplo, en el estatus del líbico en el norte de África, donde había una situación de diglosia en la que el púnico era la lengua de los rótulos monetarios y de las inscripciones oficiales ${ }^{8}$.

García-Bellido 2014: 253-258). Una carta sobre plomo en griego hallada en Ampurias (De Hoz García-Bellido 2014, n ${ }^{\circ} 29$ ) podría documentar relaciones con Sagunto, si se confirmase que el topónimo Saiganthé se refiere efectivamente a dicha ciudad. Velaza (2002: 129) plantea la posibilidad de que esta leyenda se debiera a la iniciativa de una elite que tuviera como rasgo distintivo un origen griego (fuese ficticio o real).

${ }^{8}$ El uso del líbico se restringía a la epigrafía funeraria y votiva, en estelas y en paredes rocosas. No obstante, Chaker (2013) ve el "embrión" de una posible epigrafía oficial líbica en
Centrémonos en Sicilia para analizar algunos ejemplos de este fenómeno. Esta isla es un laboratorio perfecto de contactos culturales, entre los que sobresalen los lingüísticos y epigráficos (Tribulato 2012): los pueblos indígenas, que hablaban al menos tres lenguas diferentes (sículo, sicano y élimo), interactuaron con los colonos fenicios y griegos desde el siglo $\mathrm{X}$ a. C. Posteriormente, como consecuencia de los conflictos bélicos que se desarrollaron en Sicilia desde el siglo V a. C. entre griegos, cartagineses y romanos, se introdujeron nuevos elementos lingüísticos en la isla. Estos contingentes, a su vez, se sirvieron de soldados extranjeros, provenientes de la península itálica, península ibérica, Baleares y norte de África, pagados a sueldo para defender sus intereses (Tagliamonte 1994; Quesada 1994; Castrizio 2000; Graells 2014). Algunos de ellos se asentaron allí tras la guerra.

Estos mercenarios eran pagados con monedas emitidas por las ciudades donde estaban instalados, cuyas leyendas habitualmente exhibían un etnónimo en genitivo plural, en lengua y alfabeto griegos, salvo raras excepciones, como las series con inscripción élima de Segesta y Eryx (Willi 2008: 43-44; Simkin 2012: 176). El primer rasgo remarcable de estos epígrafes es que, aunque efectivamente contienen rótulos que representan una identidad colectiva, se trata de una denominación etic, construida por un agente externo a partir de algunos elementos que pueden resultarles comunes dentro de un grupo tan heterogéneo como Sileraioi (etnónimo que no se conoce por ninguna otra fuente), posiblemente lucanos (Castrizio 2000: 43, 54-55), o Tyrrhenoi, etruscos ${ }^{9}$. Por otra parte, la lengua griega, en la que estaban redactadas mayoritariamente las leyendas, obviamente no era la suya, lo que constituye el segundo punto de interés de este numerario, y que se debe a que la producción monetaria siciliana estaba directamente asociada con la cultura griega (Simkin 2012: 176). Sin embargo, no todos los mercenarios acuñaron moneda en griego: los hispanos asentados en Morgantina $^{10}$ fabricaron numerario en latín con la le-

un conjunto de dedicaciones monumentales en honor de monarcas y notables locales procedentes de Dougga (norte de Túnez) fuertemente influenciadas por la cultura epigráfica púnica. El púnico era la lengua "culta" del reino númida, y su uso oficial es especialmente claro en las leyendas monetales (Quinn y McCarthy 2015: 171-174). Sobre el papel de las autoridades númidas en este proceso, además de otros factores, cf. Kerr 2010: 52-53; Bridoux 2014: 182.

La leyenda de estas monedas es Tyrrhe, y la reconstrucción más verosímil es "Tyrrhenoi". Sobre otras comunidades de mercenarios que acuñaron moneda en Sicilia, como los Kampanoi o los Mamertini, cf. Tagliamonte 1994: 243 ss.; ImIt Sicilia, Messana 1, p. 1511.

${ }^{10}$ La presencia de hispanos como soldados a sueldo en Sicilia está documentada desde 480 a. C., año de la batalla de Himera (Diodoro 11, 1.5) gracias a los testimonios literarios. Se- 
yenda Hispanorum en un momento posterior a 211 a. C. (Erim 1958; Caccamo Caltabiano 1985 y 2004; García-Bellido 1995: 146-147; Beltrán 2011b: 66-69) (Fig. 4). En este contexto siciliano de finales del siglo III a. C., la elección del latín por parte de los hispanos resulta excéntrica.

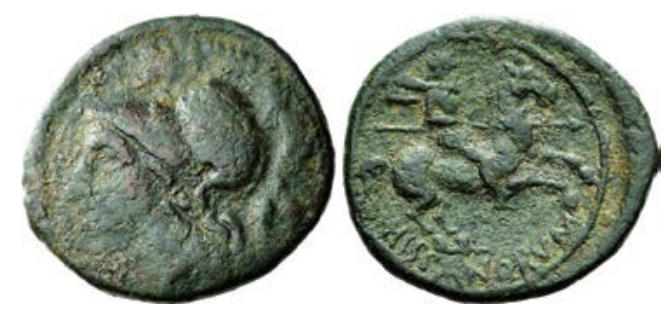

Figura 4. Bronce de Morgantina con la leyenda Hispanorum en el reverso (6,9 g.). A. Vico, Ex HSA-11167. Subasta 132 (noviembre 2012), lote 703 (https://www.numisbids.com/n. php? $=$ lot\&sid=379\&lot=703).

Estas piezas han atraído la atención de historiadores y epigrafistas desde hace décadas, fundamentalmente porque uno de los tipos de reverso, el jinete con lanza, ya presente en el numerario de Siracusa bajo Agatocles e Hierón II, fue posteriormente uno de los más utilizados en las monedas paleohispánicas de la Citerior (cf. DCPH II: 166-167; García-Bellido 1995: 146-147 y Beltrán 1998: 105-115); aunque aquí me centraré únicamente en la leyenda, tanto en la elección lingüística como en su contenido. En cuanto al primer asunto, es obvio que la comunidad de hablantes de Morgantina de finales del siglo III a. C. no utilizaba el latín como lengua de comunicación habitual (las inscripciones de esta ciudad están escritas en griego, cf. Stone 2014, p. 13; también hay un ejemplar en sículo: ISic 2954), y asimismo es complicado asumir que el latín fuera, en un momento tan temprano como ese, la lengua utilizada por los mercenarios hispanos. Por lo que respecta al contenido de la leyenda, Hispanorum es un exoetnónimo que posiblemente se fraguó en el curso del servicio militar de este contingente, en un contexto romano, para establecer una diferencia con otros grupos de auxiliares. Esta apelación, que los mercenarios asumieron pese a su más que probable diversidad de orígenes hispanos, queda patente en Livio y en el bronce de Áscoli: Livio (Liv. 25, 30) se refiere a ellos como Hispani auxiliares (Hispanorum auxiliaribus) y el autor del Bronce de Áscoli (CIL I ${ }^{2}$ 709) registra la primera concesión colectiva de ciudadanía a unos equites hispanos, englobando bajo este

gún relata Livio (Liv. 25, 30), un contingente de Hispani se instaló en el territorio de Morgantina tras haberse pasado al bando romano durante el sitio de Siracusa en 212 a. C. término a jinetes ibéricos y vascones de diversas procedencias.

\section{El PERIODO MEDIO-TARDORREPUBLICANO. HisPANIA}

Esta situación en la que la autoridad emisora de la moneda utiliza una lengua diferente de la propia de la comunidad se vuelve particularmente frecuente durante la expansión romana en el occidente mediterráneo. A lo largo de este periodo se aprecia un interesante proceso de adopción de una lengua, el latín, no por imposición sino por necesidad de adaptación a las nuevas circunstancias sociopolíticas, comenzando por las inscripciones oficiales (producidas tanto por romanos en territorio conquistado como por las elites), siguiendo por las inscripciones públicamente visibles y terminando por las inscripciones de tipo privado y circulación más restringida. La llegada de Augusto aceleró sustancialmente esta situación, cuestión sobre la que se volverá.

Dado que la latinización fue un proceso lento y progresivo, sus avances se aprecian de forma muy paulatina y se documentan situaciones particularmente complejas de décalage entre las monedas y el registro epigráfico, como ocurrió en la península ibérica, donde la llegada de Roma estimuló decisivamente tanto la fabricación de moneda por parte de las comunidades locales (Ripollès 2005a: 192 y ss., 2005b: esp. 80 y ss.) como la escritura sobre soporte no perecedero (Beltrán 2005: esp. 34 y ss.) ${ }^{11}$.

Por lo que respecta a la epigrafía monetaria, se da una diferencia fundamental entre las dos provincias hispanas en lo concerniente a la elección de la lengua y la escritura: mientras que las cecas de la Citerior acuñaron moneda con letreros paleohispánicos (ibéricos, celtibéricos y "vascónicos"); las de la Ulterior optaron por el latín mayoritariamente o, al menos, por exhibir el topónimo en alfabeto latino, una elección lingüística probablemente relacionada con las circunstancias de asentamiento de los colonos romanos e itálicos en cada región (sobre las diferencias numismáticas entre Citerior y Ulterior, especialmente en lo tocante a la lengua de las leyendas y a la iconografía ${ }^{12}$, cf. Ripollès 2005a: 198, 2005b: 85-86; Beltrán 2011a:

\footnotetext{
11 Sobre el latín en las leyendas monetales del occidente del Imperio Romano, cf. Burnett 2002. Sobre la latinización de las leyendas monetales de Hispania, cf. Untermann 1995; Mora 2004; Beltrán 2004.

12 Las diferencias en la elección de los tipos son también muy notorias, ya que en la Citerior predomina el anverso con cabeza masculina y el reverso con jinete; mientras que en la Ulterior hay mucha mayor variedad iconográfica.
} 
36-38). Aunque no voy a entrar en esta cuestión, me interesa subrayar aquí que, aunque en momentos y con ritmos diversos, las leyendas monetarias fueron los primeros textos redactados en latín por los hispanos, el primer género textual (si puede considerarse tal) que reflejó los efectos de la latinización.

A diferencia de la Citerior, en el territorio de la Ulterior se establecieron asentamientos romanos que emitieron moneda desde los primeros compases de la conquista. El caso más claro es el de Carteia (Chaves 1979), antiguo núcleo púnico refundado en 171 a. C. como Colonia Latina Libertinorum para albergar a los descendientes de soldados romanos y mujeres ibéricas. Las leyendas de su numerario, fabricado a partir de 130 a. C., estaban obviamente en latín, incluso cuando sus habitantes probablemente no hablaban esta lengua sino púnico ${ }^{13}$.

Curiosamente, las primeras leyendas monetarias en latín (o, al menos, en alfabeto latino) no se dan en una fundación romana sino en una comunidad indígena, concretamente, en la ceca de Obulco (Porcuna, Jaén, $M L H$ A.100), que acuñó una enorme cantidad de bronce y fue un importante centro de producción y distribución agrícola. La aparición de las primeras monedas de esta ceca, una de las más precoces la península ibérica, está directamente relacionada con los primeros asentamientos romanos en las postrimerías de la II Guerra Púnica. Desde el principio, al menos uno de sus rótulos, el referido al topónimo, en el anverso, fue grabado en alfabeto latino (Fig. 5). De hecho, en la primera emisión el reverso contiene un rótulo en latín, la referencia a los magistrados (aid(iles) $\operatorname{ar}($ genti?)). La segunda emisión, datada en la primera mitad del siglo II a. C. (DCPH II: 290), exhibe un rótulo bilingüe consistente en el topónimo en latín e ibérico (Obulco / ipolka) $)^{14}$; y, de ahí en adelante, las monedas de esta ceca conservan en el anverso el topónimo en caracteres latinos y en el reverso se graban

\footnotetext{
${ }^{13}$ Sobre la población de Carteia, de origen fenicio, cf. Padilla 2011, donde, junto a los hispanorromanos a los que se refiere Livio y a los itálicos que se instalaron posteriormente allí, también se documenta población púnica que pasó a formar parte de las elites de la colonia. La transformación de ciudad púnica a colonia latina no está reflejado de forma abrupta en la arqueología carteyense (Bendala 2000; Roldán et alii 2006: 541-542) ni en la epigrafía (las inscripciones latinas más antiguas de esta colonia, sobre tégula, son de época augústea, cf. Del Hoyo 2006: 465). Sobre los cambios en las ciudades púnicas hispanas reflejados en la numismática durante la romanización, cf. Chic 2000.

${ }^{14}$ La relación lingüística entre los dos topónimos de esta ceca (Obulco en alfabeto latino e ibolka o ipolka en signario ibérico meridional) no es evidente. Cf. Correa 1983, 2009: $282-$ 283; De Hoz 2010: 92. Me inclino a pensar que Obulco es la transcripción en alfabeto latino del topónimo local. Sobre la ceca de Obulco, cf. Arévalo 1999.
}

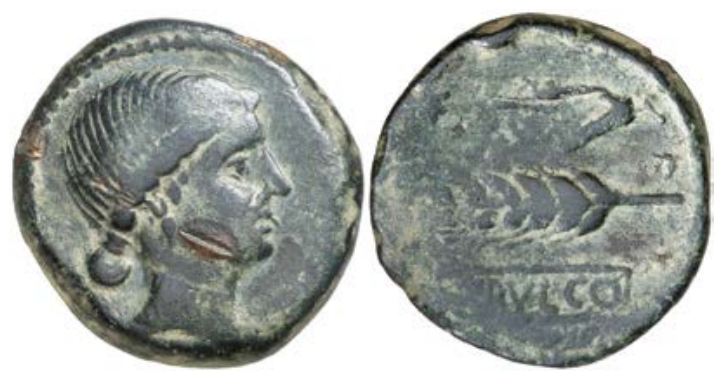

Figura 5. Bronce de Obulco, $1{ }^{\circ}$ emisión de la ceca con leyenda en alfabeto latino Obulco (DCPH p. 290 n. 1, 18,89 g.). Áureo y Calicó, 3/6/2015, lote 4515 (https://www.acsearch.info/search. html?id=2510624).

dos nombres personales de raigambre local, correspondientes a los dos magistrados monetarios probablemente, tanto en el sistema de escritura vernáculo como en alfabeto latino. Pese a esta elección lingüística y escrituraria afín a la cultura romana en la expresión del topónimo, los tipos monetarios de Obulco responden claramente a referentes que no son romanos: la cabeza femenina en anverso con moño bajo y la espiga y el arado en el reverso son elementos iconográficos recurrentes en el sur de Hispania ${ }^{15}$.

En claro contraste, el registro epigráfico de Obulco no documenta una adopción tan inmediata del latín o del sistema de escritura de los romanos (sobre la lengua hablada en Obulco en época prerromana, cf. Correa 1983, 2009: 282-283; Beltrán 2005: 26; Herrera 2015: 75 ss.). De hecho, su registro epigráfico es extremadamente débil. Hasta la fecha, se ha hallado un grafito datable a comienzos del siglo I d. C. escrito en signario ibérico meridional (Arteaga y Correa 1998; Correa 2008, $\mathrm{n}^{\circ}$ 8; Herrera 2016: 156) y una inscripción de difícil interpretación, un esgrafiado sobre un fragmento escultórico de pata de caballo que pudiera estar escrito en alfabeto meridional o griego $(M L H$ H.12.1, cf. De Hoz 2010: 145, 361). Carmo, cuyo taller numismático estaba vinculado probablemente al de Obulco, comenzó a producir moneda con leyendas latinas en un momento también muy precoz, durante el último tercio del siglo II a. C. ${ }^{16}$

15 Sobre estos elementos iconográficos, para los que se debate si tienen un origen fenicio o turdetano, cf. García-Bellido 1990; Arévalo 2002-2003: 250-252.

16 Las primeras acuñaciones de Carmo se fechan en torno a 145 o a comienzos de la década de 140-130 a. C. Los grabadores de los cuños de Obulco y Carmo estuvieron en estrecho contacto, si no fueron los mismos (Chaves 2001: 357). Carmo, que ya recibió una comunidad fenicia en época tartésica, fue una de las ciudades más relevantes de la Turdetania (Ptolomeo y Estrabón). Fue un enclave púnico y, posteriormente, bárquida (a $\mathrm{p}$. 237 a. C.). Desde mediados del siglo II a. C., se afianza allí la administración romana. Sobre la ciudad romana de Carmona, 
La redacción de los letreros en latín (o en alfabeto latino, y compatibles lingüísticamente con el latín) no es un fenómeno exclusivo de Obulco. A lo largo del siglo I a. C. más de medio centenar de comunidades de la Ulterior emiten numerario con rótulos en alfabeto latino, conformando el conjunto numismático llamado "hispanorromano". La elección linguiística de estas inscripciones es particularmente interesante, puesto que el registro epigráfico coetáneo (ss. II-I a. C.) confirma la vigencia de la lengua epicórica y el sistema de escritura meridional (se han recuperado casi 90 textos en escritura local, cf. BDHesp). De hecho, en el resto de elementos de las monedas de Obulco y las "hispanorromanas", concretamente su iconografía, sigue prevaleciendo la cultura local (Mora 2012: 747 y ss.) ${ }^{17}$. Teniendo esto en cuenta, ¿es lícito interpretar la elección del alfabeto latino en clave de identidad como una exhibición de filorromanidad ("doble identidad", "identidad múltiple", etc.) o, por el contrario, no sería preferible entender esta elección como un uso práctico del alfabeto latino con el fin de que los rótulos monetarios tuvieran mayor difusión en el resto de habitantes de la Ulterior ya que, como parece, el latín (y su sistema de escritura) fue una lingua franca en la región ${ }^{18}$ ?

La latinización de las leyendas monetarias de la Citerior comienza a percibirse de forma generalizada a mediados del siglo I a. C., aunque, como en la Ulterior, hubo cecas de fundaciones romanas y, también, de comunidades indígenas que grabaron rótulos en latín ya en el último tercio del siglo II a. C. (Valentia, Saguntum, cf. Ripollès 1988; Ripollès y Llorens 2002). Todo apunta a que Roma no se injirió en la política linguiística de las ciudades, salvo en el caso de las colonias de nueva planta, de las que sí que se esperaba que su numerario exhibiera rótulos en latín (piénsese en el estatuto colonial de Sagunto ${ }^{19}$, por ejemplo, concedido en el tercer cuarto del siglo I a. C.: la cronología de algunas de sus emisiones monetarias bilingües ibérico-latinas llega hasta la década de los 30 a. C.). Por tanto, la latinización de las leyendas fue

cf. Caballos 2001, con trabajos sobre su ceca Chaves 2001 y sobre la epigrafía de época republicana Stylow 2001. Véase también $D C P H$ II: 84-85.

${ }^{17}$ La descripción del papel de las elites indígenas en la metamorfosis institucional de las ciudades de la Hispania Ulterior y su reflejo en las monedas y sus leyendas se puede consultar en Chaves 1994, Chic 1998, Mora 2005, Chic 2007 y 2008. Sobre la numismática de época republicana en la Ulterior, Chaves 1998 (esp. 149-163) y Jiménez 2014.

18 Sobre el latín como lingua franca del sur peninsular, reemplazando al púnico, cf. Beltrán 2011a: 41-43.

19 Sagunto debió de ser colonia latina a lo largo de la segunda mitad del siglo I a. C., momento en el que pasó a municipium. en el 56 a. C. Según Cicerón, era una ciudad federada. El epígrafe CIL II 3827 datado en el 4/3 a. C. confirma el estatuto municipal de la ciudad. un proceso, en cierto modo, voluntario y que respondió a las necesidades culturales, sociopolíticas y económicas del periodo: de hecho, en Sagunto, como se ha dicho, todo el conjunto epigráfico preaugústeo está en ibérico. A mediados del siglo I a. C. la ciudad de Osicerda emite numerario bilingüe, en ibérico y latín, cuando en sus entornos se seguía utilizando el signario ibérico para la epigrafía de tipo privado: numerosos grafitos del Bajo Aragón (Teruel) están fechados a lo largo del siglo I a. C., aunque algunos materiales pueden datarse con mayor precisión a mediados de esta centuria, como las pesas de telar de Mas de Moreno, o incluso más adelante, como el fragmento de terra sigillata con inscripción ibérica de Masico de Ponz (Alcañiz, Teruel) (Gasca y Fletcher 1989-1990, nº 6).

Creo que ver intentos de "resistencia lingüística" en las últimas leyendas en lengua local de cada ceca, en ocasiones bilingües (Celsa, Osicerda, Saetabi, Gili, por ejemplo), tiene difícil justificación histórica, puesto que esta afirmación estaría postulando una política romana en esta dirección; pese a que parece evidente que cada comunidad fue libre de acuñar y diseñar su numerario hasta la llegada de Augusto. Este proceso queda ilustrado en las cecas de Segobriga y Clunia, donde las leyendas, en lengua celtibérica, abandonaron el sistema de escritura paleohispánico y adoptaron en alfabeto latino (Clounioq(um), BDHesp Mon.67.2, y Segobris, BDHesp Mon.89.3), al tiempo que se mantenían los elementos iconográficos locales (cabeza masculina a derecha en el anverso, jinete lancero en el reverso) en los diseños. Este uso del alfabeto latino en la producción numismática de Clunia y Segobriga no es un hecho aislado: en el resto de epigrafía celtibérica, redactada en lengua celtibérica sobre soportes típicamente celtibéricos como las téseras de hospitalidad, también se documenta la transición del sistema de escritura local al alfabeto latino a lo largo del siglo I a. C. ¿Realmente puede interpretarse el alfabeto latino como una "victoria" de la cultura romana en la Celtiberia? ¿O fue una elección de los celtíberos, ya que el alfabeto latino les permitía transcribir su lengua con mayor precisión que el semisilabario paleohispánico? En estos términos podría incluso plantearse si el uso del alfabeto latino fue un retroceso o un avance para la conservación de la lengua celtibérica.

\section{El PERIOdo Altoimperial: El SUR DE Hispania Y EL NORTE DE ÁFRICA}

Las lenguas paleohispánicas habían sufrido un claro desgaste a lo largo de más de doscientos años de contacto con el latín como lengua $\mathrm{H}$, a tenor de la evo- 
lución del registro escrito: la presión sociopolítica y cultural las relegó al ámbito privado de forma tangible en una horquilla de tiempo próxima al cambio de Era. La explosión epigráfica experimentada en los territorios dominados por Roma, vinculada a la representación del emperador y a la de los notables locales en los espacios públicos, fue el golpe de gracia para las culturas epigráficas locales, ya que la lengua en la que este tipo de textos se escribían en occidente era el latín. Naturalmente, el dominio de Roma conllevó el uso de la lengua de la urbs para la expresión epigráfica pública (y, progresivamente, también para la esfera privada) de los territorios conquistados; pero no implicó que los habitantes de estas regiones sustituyesen súbitamente todos sus referentes culturales por sus equivalentes romanos. Es bien sabido que el Imperio romano era un territorio con innumerables sincretismos culturales. Y, pese a ello, el uso de lenguas locales en inscripciones augústeas y postaugústeas sigue interpretándose frecuentemente en términos de "resistencia cultural" cargada de contenido ideológico, del conquistado frente al conquistador. Los elementos de la moneda, especialmente los tipos y las leyendas, son entendidos frecuentemente desde dicho punto de vista ${ }^{20}$.

Los pueblos paleohispánicos no produjeron numerario con leyendas en lenguas locales desde mediados del siglo I a. C., bien porque las cecas locales cerraron, o bien porque las que permanecieron abiertas emitieron moneda con rótulos en latín. Sólo en Gadir, Malaka, Abdera y Ebusus se fabricó moneda con rótulos escritos en una lengua diferente durante la segunda mitad de la centuria antes del cambio de Era (Abdera y Ebusus hasta más adelante incluso, como se indicará a continuación). Podría decirse que el púnico fue la única lengua del occidente romano que "sobrevivió" al avance del latín en los letreros monetarios, y lo hizo no sólo en Hispania y sino también en el norte de África, donde varias cecas acuñaron monedas bilingües (Estarán 2016: 465-504).

En este contexto histórico y linguiístico, en el que el sur de la península ibérica había sido testigo de más de dos siglos de presencia romana, creo que cabe preguntarse hasta qué punto es acertado hablar de Roma como potencia invasora y del latín como lengua del poder. Quizá sería más oportuno analizar los textos producidos por estas comunidades no desde la óptica de la resistencia al invasor (cf. nota 2) y de la voluntad de preservar su cultura local (incluida su lengua, cf. Quinn 2003 y 2010), sino desde su particular modo de expresar simultáneamente su pertenencia al Imperio

20 Véase, por ejemplo, Keay 1992 para Turdetania. Una crítica al uso de "resistencia cultural" puede encontrarse en Häussler 2013: 22-23.
Romano y su calidad de hispanopúnicos ${ }^{21}$. A juzgar por los testimonios epigráficos (sobre todo grafitos), parece evidente que la lengua púnica continuó teniendo vitalidad en el mediodía hispano hasta bien entrado el siglo I d. C., momento en el que los núcleos urbanos ya estaban incluidos en la esfera de Roma, en términos institucionales, políticos, sociales y de cultura material. La elección lingüística parece independiente del estatuto político de la ceca (v. Burnett 2002: 37), como queda patente si se comparan los rótulos de las ciudades que obtuvieron el estatuto municipal en época preaugústea o augústea y los de los municipios flavios.

Firmum Iulium Sexi consiguió el estatuto municipal tras la Guerra Civil. A partir de ese momento, en la última emisión antes del cierre de la ceca, dos letras neopúnicas $(a, y)$ y dos atunes, que son referentes iconográficos plenamente locales, acompañan la leyenda latina, F. I. Sexs (Fig. 6). Sin embargo, el registro epigráfico de Sexs sólo comenzó a acusar epigrafía latina de forma habitual a partir de finales del siglo I d. C. (CILA IV: 223-235), junto con el desarrollo de nuevos equipamientos urbanísticos como el foro, que se construyó a lo largo de la primera mitad del siglo I d. C. Hasta este momento, parece que la lengua empleada a nivel no oficial / privado era el púnico (Molina 1986: 208; López Castro 2007)²2.
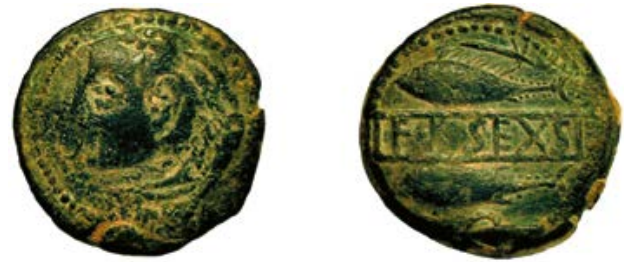

Figura 6. Bronce de Firmum Iulium Sexs con leyenda latina y dos letras púnicas en el reverso (RPC 123-A3; 15,34 g). Colección J. A. Herrero, Subasta 28/5/2015, lote 95 (https://www.acsearch.info/search.html?id=2004501).

Por lo que respecta a Gades, no hay consenso sobre la fecha de adquisición de su estatuto municipal; pero lo cierto es que ocurrió antes de la época flavia con seguridad. Pese a que Gadir quedó inserto en los circuitos comerciales romanos a partir del 206 a. C., y que su foedus se renovó en 78 a. C. (López Castro 1991), su numerario siguió exhibiendo rótulos e iconografía púnicos. El cambio de elección lingüística en su moneda

${ }^{21}$ Línea trabajada por Barreca 1986: 43-52; Vismara 1990 y Machuca 2017. Cf. también Adams 2003: 208-209, 753, "identidad doble" o "mixta"; Domínguez Monedero 2000; Ferrer y Álvarez Martí-Aguilar 2009; Álvarez Martí-Aguilar 2012: 5455; Ortiz 2012.

${ }^{22}$ Véase p. ej. un grafito púnico sobre Campaniense B (I a. C.) en López Castro 1995: 219. 
llegó de la mano de otras transformaciones en su metrología y en sus tipos (DCPH II: 152), así como de la construcción de equipamientos inscribibles claramente en la cultura romana, entre los que destaca el teatro o el Arco de los Blancos, a finales del siglo I a. C.; pero ninguna inscripción en latín, con la excepción de unos sellos sobre ánfora (ELRH SC1-4 y CIL I 2654n). La epigrafía latina de Gades se desarrolló más tarde, a lo largo del siglo I d. C. (González 1982; López y Ruiz 1995: 11 y 15) y una de sus características más singulares es que un tercio de las inscripciones contienen nombres con raíces semíticas (López Castro 2007: 119-120).

Una situación opuesta la plantean Abdera (Adra, Almería) y Ebusus (Ibiza). Fueron promocionadas a municipios durante el gobierno de los Flavios (Galsterer 1971: 70) y, sin embargo, ya incluían inscripciones latinas en su numerario en época altoimperial, dando lugar a monedas bilingües (Estarán 2016, P2, P3) y a iconografías "mixtas" en las que, junto con la efigie del emperador, aparecen sintetizados los elementos iconográficos locales precedentes, un fenómeno también documentado en Oea, Sabratha y Leptis Magna (Mora 2000: 162), cecas que se abordarán más adelante. Este empleo numismático del latín contrasta con el registro epigráfico de Almería e Ibiza, donde las inscripciones latinas sólo se generalizaron a lo largo del siglo I d. C. (v. Lázaro 1980 para la primera; Castelló 1988 y Juan 1988, Sánchez 2004 para la segunda). En contraste, otras ciudades, como Malaka, nunca introdujeron leyendas en latín, sino que sus rótulos estuvieron redactados únicamente en púnico hasta el cierre de la ceca ${ }^{23}$, en consonancia con el material epigráfico (Zamora 2013: 371-372).

Esta expresión de simultánea adscripción al ámbito cultural romano y púnico en las representaciones monetarias se constata también en la numismática tripolitana. Pensemos en Oea, cuyas fechas exactas de promoción a municipio y colonia se desconocen ${ }^{24}$. Allí se acuñaron emisiones bilingües bajo Augusto y Tiberio con brevísimos rótulos latinos consistentes en una $C \mathrm{o}$, con Tiberio, en el nombre del emperador, pese a que el

${ }^{23}$ Existe cierta controversia en cuanto a la cronología de una de las últimas series que, según Campo y Mora 1995, podría situarse entre $15 / 14$ y 10 a. C. y, según $R P C$ y $D C P H$, en la segunda mitad del II a. C. En cualquier caso, dejando esta emisión aparte, sí hay consenso en datar la fabricación de otras series, al menos, hasta 27 a. C. Sobre la personalidad de la producción numismática malacitana, cf. López Castro y Mora 2002: 211214. Parece ser que esta elección lingüística podría ir en consonancia con los datos que se desprenden de la cultura material y equipamiento urbanístico de la ciudad, que, hasta el cambio de Era, muestran una carácter eminentemente púnico: v. Mayorga et alii 2005, retomando el clásico trabajo de P. Rodríguez Oliva, "Málaga, ciudad romana".

24 Seguramente recibió el estatuto colonial en la década de los 60 del siglo II d. C. (Mattingly 2005: 203). púnico siguió hablándose allí al menos hasta el siglo II d. C., a tenor del relato de Apuleyo de Madaura, quien relata la terqueza de un familiar suyo por expresarse púnico o, en todo caso, griego; pero en ningún caso, latín, porque "no quería ni podía" (Latine loqui neque vult neque potest, Apul., Apol XCVIII, 8-9). La epigrafía de Oea es, además, muy escasa, incluso a lo largo de todo el siglo I d. C., tanto en latín como en púnico.

La elección lingüística de las monedas de $S a$ bratha, oppidum peregrinum que consiguió promocionar a civitas libera et immunis bajo Augusto o Tiberio, es distinta de Oea y Lepcis Magna, lo que quizá podría deberse al arraigo de la lengua líbica en esta ciudad con respecto de las otras dos (Mùrcia 2011: 241; Estarán 2016: P11). Aquí las leyendas monetarias fueron fundamentalmente púnicas, con algunas básicas introducciones de rótulos latinos consistentes en la palabra Caesar o en la letra $C$. Llega un momento en el que este numerario bilingüe deja de producirse y se vuelve a la lengua púnica en las últimas emisiones. De Sabratha proceden una decena de inscripciones latinas y una quincena de púnicas datables en el siglo I d. C. (IRC, Amadasi 1987).

Por otra parte, el fascinante material epigráfico y numismático de Lepcis Magna, capital de la Tripolitania (con una sobresaliente cantidad de inscripciones púnicas y latinas y el mayor índice de bilingües del occidente, cf. Estarán 2016, P13 y P38-P50) aporta una gran cantidad de información sobre la expresión pública de la romanidad en las provincias durante el primer siglo de nuestra Era. Los cambios en la elección lingüística se perciben claramente a partir de Augusto.

En lo que respecta a las inscripciones sobre moneda, escritas sólo en púnico hasta el gobierno del Princeps, pasan a incluir escuetos textos en latín junto con las leyendas púnicas (donde se especifica el topónimo) bajo Augusto y Tiberio. Estas leyendas consisten en la alusión al emperador: Caesar (Estarán 2016, P13) (Fig. 7). En cuanto a la epigrafía no monetaria, se han hallado hasta la fecha (IRT) 20 inscripciones en latín datables en el siglo I d. C., todas procedentes de espa-

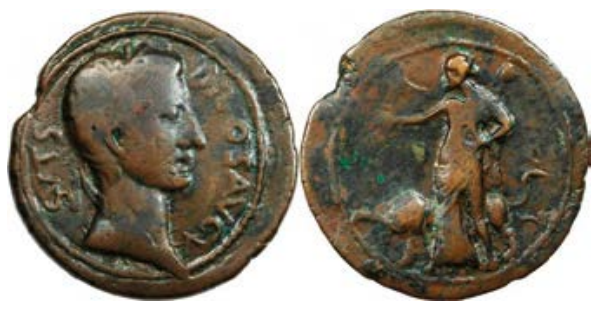

Figura 7. Bronce de Lepcis Magna con cambio de dirección en la segunda parte de la leyenda del anverso (RPC 848, 25.81 g). Stack's Bowlers Galleries, Baltimore 15/11/2012, lote 11714 (https://www.acsearch.info/search.html?id=1431512). 
cios públicos (el teatro, el mercado, un templo junto al teatro, el Forum Vetus, un arco y el Chalcidicum, de época de Augusto o Tiberio) y consistentes en dedicaciones a los emperadores o a su familia; mientras que las inscripciones púnicas contemporáneas no sólo estaban ubicadas en los ámbitos públicos sino también, a diferencia de las latinas, a los privados, como se desprende de los epitafios en urnas cinerarias (Amadasi 1987: no 19, 33-66, 69-72; cf. Cooley 2012: 250261). Es muy significativo que el $99 \%$ de las inscripciones bilingües proceda del mercado, del teatro o del foro, donde hay numerosas inscripciones latinas. En ellas la versión púnica del texto es normalmente una traducción breve de la latina y está colocada en una posición menos visible. Por tanto, la elección lingüística de Lepcis Magna, tanto en monedas como en inscripciones, nos muestra cómo el latín se empleaba básicamente para la representación pública (y también) oficial de la ciudad y de sus notables locales; mientras que la lengua de uso cotidiano fue el púnico en los primeros siglos después de nuestra Era (Mùrcia 2011: 238).

$$
* * *
$$

Mediante este rápido recorrido por la numismática pre y co-romana he querido reflexionar sobre la identificación de una comunidad con su lengua, y sobre si esta identificación, de existir, quedaba reflejada en las monedas. He tratado de exponer la importancia de la contextualización histórica de cada producción numismática antes de extraer conclusiones sobre la función simbólica de la lengua, que actualmente tiende a aducirse para este tipo de textos.

La ubicación de las leyendas monetarias en sus circunstancias históricas y la comparación de su elección lingüística con la del registro epigráfico correspondiente permite distinguir con mayor nitidez aquellos casos en los que, efectivamente, la lengua tiene una función simbólica que sirve para construir una identidad cívica, de otro tipo de inscripciones monetarias en los que la elección lingüística o del sistema de escritura se debe a otro tipo de causas (cambio lingüístico, cambios en la situación económica o política).

Como se ha visto, el uso de la lengua como elemento cohesionador de una identidad colectiva ocurre de manera excepcional, en el marco de conflictos externos o de evocación de un pasado mítico. La lengua de las monedas se constituye así en un instrumento ideal para aglutinar los sentimientos de una comunidad que se siente amenazada por otra, o que necesita reforzar esta unidad en un momento puntual. En estos casos, la lengua no es el único elemento de la moneda que sirve para la exhibición de la identidad: la iconografía tiene un papel fundamental al respecto, incluso mayor que el de las leyendas, dada la inmediatez y la expresividad de su mensaje. Los ejemplos más claros de ello son las monedas de la Guerra Social y la revuelta judía.

Sin embargo, como he tratado de demostrar, esta expresión tan explícita de la identidad colectiva mediante la elección de la lengua de las leyendas no es la norma en la producción numismática. A lo largo de los dos últimos siglos a. C. y del primero d. C. se produjo en el occidente romano un cambio lingüístico de gran magnitud, cuyas causas fueron sociopolíticas y económicas, que supuso la sustitución de las lenguas locales por el latín. La mayor parte de los casos de incoherencia entre la lengua de las leyendas monetarias y la del registro epigráfico ha de explicarse a partir de estas circunstancias históricas, y no sólo a partir de una voluntad de expresión de la identidad. En este contexto, creo que la coexistencia de letreros púnicos juntos a los latinos en las monedas bilingües de finales del I a. C. y comienzos del I d. C. (así como los ibéricos, en las bilingües de los siglos II-I a. C.), no deben entenderse como metáforas de la resistencia local al inexorable avance de la cultura y la lengua de Roma; sino como expresiones de la continuidad del carácter local de las ciudades que emitían esta moneda (reflejada, por otra parte, también en la iconografía), siendo conscientes de su pertenencia al Imperio Romano.

Efectivamente, como afirmaba F. Millar (1993: 257), la moneda es uno de los símbolos más explícitos de una ciudad; pero no exactamente de su realidad cultural y lingüística, sino de la selección de elementos por la cual ésta se proyectaba hacia el exterior. Estas singulares características de la moneda (que conjuga información epigráfica, iconográfica, metalográfica y metrológica, así como su fabricación serial) combinadas con los datos epigráficos, hacen de ella un instrumento idóneo para analizar las reacciones de las comunidades cívicas ante estímulos o amenazas externas, que abundaron en los dos últimos siglos a. n. e.

\section{FUENTES}

BDHesp: Banco de datos de lenguas paleohispánicas "Hesperia", <http://hesperia.ucm.es> (31/10/2017).

CIL: Corpus Inscriptionum Latinarum.

CILA IV: Corpus de Inscripciones Latinas de Andalucía, vol. IV: Granada, M. Pastor, Sevilla, 1991.

DCPH: Diccionario de cecas y pueblos paleohispánicos, M. P. García-Bellido y C. Blázquez, Madrid, 2001, 2 vols. 
ELRH: Epigrafía latina de época republicana de Hispania, B. Díaz, Barcelona, 2008.

ImIt: Imagines Italicae. A corpus of Italic inscriptions, M. Crawford (ed.), London, 2011.

ISic: I Sicily: a digital corpus of Sicilian inscriptions, J. Prag, <http://sicily.classics.ox.ac.uk> (31/10/2017).

RPC I: Roman Provincial Coinage, vol. 1. From the death of Caesar to the death of Vitellius (44 BC$A D$ 69), A. M. Burnett, M. Amandry y P. P. Ripollès, London, 2006.

\section{BIBLIOGRAFÍA}

Adams, J. N. 2003: Bilingualism and the Latin language, Cambridge.

Adams, J. N. y Swain, S. 2002: "Introduction", J. N. Adams, M. Janse y S. Swain (eds.), Bilingualism in Ancient Societies, Oxford, 1-21.

Álvarez Martí-Aguilar, M. 2012: "Turdetania fenicia: pasado y prestigio en el occidente romano", B. Mora, G. Cruz (eds.), La etapa neopúnica en Hispania y el Mediterráneo centro occidental: identidades compartidas, Sevilla, 35-58.

Amadasi Guzzo, M. G. 1987: Iscrizioni puniche della Tripolitania, Roma.

Amela, L. 2012: "Una moneda con letrero en griego de Sagunto", Arse 46, 171-180.

Arévalo, A. 1999: La ciudad de Obulco: sus emisiones monetales, Sigüenza.

Arévalo, A. 2002-2003: "Las imágenes monetales hispánicas como emblemas de Estado", Cuadernos de Prehistoria y Arqueología 28-29, 241-258. https://doi.org/10.15366/cupauam2003.29.012

Arteaga, O. y Correa J. A. 1998: "Inscripción vascular indígena hallada en Obulco (Porcuna, Jaén) y su contexto arqueológico”, J. Mangas y J. Alvar (eds.), Homenaje a José María Blázquez, Madrid, 45-58.

Barreca, F. 1986: La civiltà fenicio-punica in Sardegna, Sassari.

Beltrán, F. 1998: "De nuevo sobre el origen y la función del denario ibérico", Gabinet Numismàtic de Catalunya (ed.), La moneda en la societat ibèrica, Barcelona, 101-118.

Beltrán, F. 2004: "Imagen y escritura en la moneda hispana", F. Chaves y F. J. García Fernández, (eds.), Moneta qua scripta. La moneda como soporte de escritura: actas del III Encuentro Peninsular de Numismática Antigua. Anejos de Archivo Español de Arqueología XXXIII, Madrid, 125-140.

Beltrán, F. 2005: "Cultura escrita, epigrafía y ciudad en el ámbito paleohispánico”, F. Beltrán, C. Jordán y J. Velaza (eds.), Acta Palaeohispanica IX. Actas del IX Coloquio sobre Lenguas y Culturas Paleohispánicas (Barcelona, 20-24 de octubre de 2004) [= PalHisp 5], Zaragoza, 21-56.

Beltrán, F. 2011a: "Lengua e identidad en la Hispania romana", Palaeohispanica 11, 19-59.

Beltrán, F. 2011b: ““... et sola omnium prouinciarum uires suas postquam uicta est intellexit'. Una aproximación a Hispania como referente identitario en el mundo romano", A. Caballos, S. Lefebvre (eds.), Roma generadora de identidades. La experiencia hispana, Madrid, 55-77.

Bénabou, M. 1976: La résistance africaine à la romanisation, Paris.

Bendala, M. 2000: "Panorama arqueológico de la Hispania púnica a partir de la época bárquida”, L. Callegarin y M. P. García-Bellido, (eds.), Los cartagineses y la monetización del Mediterráneo Occidental. Anejos de Archivo Español de Arqueología XXII, Madrid, 75-88.

Bourdin, S. 2012: Les peuples de l'Italie préromaine, Roma.

Bridoux, V. 2014: "Numidia and the Punic world", J. C. Quinn y N. C. Vella (eds.), The Punic Mediterranean. Identities and identification from Phoenician settlement to Roman rule, Cambridge, 180-201.

Burnett, A. 1998: "The coinage of the Social War", A. Burnett et alii (eds.), Coins of Macedonia and Rome: Essays in Honour of Charles Hersh, London, 165-172.

Burnett, A. 2002: "Latin on coins of the Western Empire", A. Cooley (ed.) Becoming Roman, Writing Latin? Literacy and Epigraphy in the Roman West, JRA Supplementary Series 48, Portsmouth, 33-40.

Butcher, K. 2003: Roman Syria and the Near East, London.

Caballos, A. (ed.) 2001: Carmona romana, Carmona.

Caccamo Caltabiano, M. 1985: "Sulla cronologia e la metrologia delle serie Hispanorum", Quaderni Ticinesi: Numismatica e antichità classiche 14, 159-169.

Caccamo Caltabiano, M. 2004: "Nuove prospettive dell'indagine sulla monetazione siciliana di 'età romana", Nuove prospettive della ricerca sulla Sicilia del III sec. a. C. Archeologia, Numismatica, Storia, Messina, 50-75.

Campana, A. 1987: La monetazione degli insorti italici (91-87), Soliera.

Campana, A. 2014: "Unpublished denarius from the Bellum Sociale", Omni 8, 33-40.

Campo, M. y Mora, B. 1995: Las monedas de Malaka, Madrid. 
Castrizio, D. 2000: La monetazione mercenariale in Sicilia: strategie economiche e territoriali fra Dione e Timoleonte, Soveria Mannelli.

Chaker, S. 2013: "Libyque: écriture et langue", S. Chaker (ed.), Encyclopédie berbère, 28-29, Kirtēsii - Lutte, <http://encyclopedieberbere.revues.org/344> (31/10/2017).

Chaves, F. 1979: Las monedas hispano-romanas de Carteia, Barcelona.

Chaves, F. 1994: "Indigenismo y romanización desde la óptica de las amonedaciones hispanas de la U1terior", Habis 25, 107-120.

Chaves, F. 1998: "The Iberian and early Roman coinage of Hispania Ulterior Baetica", S. Keay (ed.), The Archaeology of Early Roman Baetica. Journal of Roman Archaeology Supplementary Series 29, Portsmouth, 148-170.

Chaves, F. 2001: "La ceca de Carmo", A. Caballos (ed.), Carmona romana, Carmona, 339-362.

Chaves, F. 2009: "Identidad, cultura y territorio en la Andalucía prerromana a través de la numismática: el caso de Gadir-Gades", F. Wulff y M. Álvarez (eds.), Identidades, culturas y territorios en la Andalucía prerromana, Sevilla-Málaga, 317-359.

Chic, G. 1998: "La transformación de los sistemas de convivencia: hacia la formación de las urbes en el sur de Hispania", Actas del III Congreso HispanoItaliano. Italia e Hispania en la Crisis de la República, Madrid, 295-306.

Chic, G. 2000: "La romanización de las ciudades púnicas: la aportación de la numismática”, L. Callegarin y M. P. García-Bellido (eds.), Los cartagineses y la monetización del Mediterráneo Occidental, Anejos de Archivo Español de Arqueología XXII, Madrid, 145-156.

Chic, G. 2007: "Ilipa romana: entre el prestigio y el mercado", Ilipa Antiqua. De la Prehistoria a la época romana, Sevilla, 149-170.

Chic, G. 2008: "Una perspectiva de la economía en el sur de Hispania durante la república romana", Iberia e Italia: modelos romanos de integración territorial, Murcia, 325-352.

Cooley, A. 2012: The Cambridge Manual of Latin Epigraphy, Cambridge.

Correa, J. A. 1983: "Ibérico: Caśt(i)lo, Ibolc(a), Latín; Castulo, Obulco", Habis 14, 107-113.

Correa, J. A. 2008: "Crónica epigráfica del sudeste I", Palaeohispanica 8, 281-293.

Correa, J. A. 2009: "Identidad, cultura y territorio en la Andalucía prerromana”, F. Wulff y M. Álvarez (eds.), Identidades, culturas y territorios en la Andalucía prerromana, Sevilla-Málaga, 273296
Dart, C. J. 2014: The Social War, 91 to 88 BCE. A history of the Italian insurgency against the Roman Republic, London - New York.

De Hoz, J. 2010: Historia lingüística de la Península Ibérica en la Antigüedad, II. El mundo ibérico prerromano y la indoeuropeización, Madrid.

De Hoz García-Bellido, M. P. 2014: Inscripciones Griegas de España y Portugal, Madrid.

Del Hoyo, J. 2006: "La epigrafía de Carteia", L. Roldán et alii (eds.), Estudio histórico-arqueológico de la ciudad de Carteia (San Roque, Cádiz) 19941999, Madrid, 1, 465-472.

Deutsch, R. 2012: "The coinage of the Great Jewish Revolt against Rome. Script, Language and Inscriptions", D. M. Jacobson y N. Kokkinos (eds.), Judae and Rome in Coins 65 BC-135 CE, London, 113-122.

Domínguez Monedero, A. 2000: "Monedas e identidad étnico-cultural de las ciudades de la Bética", L. Callegarin y M. P. García-Bellido (eds.), Los cartagineses y la monetización del Mediterráneo Occidental, Anejos de Archivo Español de Arqueología XXII, Madrid, 59-74.

Dubuisson, M. 1983: "Y a-t-il une politique linguistique romaine?", Ktèma 7, 55-68.

Erim, K. T. 1958: "Morgantina", American Journal of Archaeology 62, 79-90.

Estarán, M. J. 2016: Epigrafía Bilingüe del Occidente Romano. El latín y las lenguas locales en las inscripciones bilingües y mixtas, Zaragoza.

Ferguson, C. 1959: "Diglossia", Word 15 (2), 325 340.

Fernández Ardanaz, S. 1991: "Pervivencia del mundo púnico en el Mediterráneo Occidental de los siglos IV-V d. C.: estudio filológico y crítico-histórico de los testimonios literarios", Antigüedad y Cristianismo 8, 137-167.

Ferrer, E. y Álvarez Martí-Aguilar, M. 2009: "Comunidad cívica e identidad en la Iberia púnica”, F. Wulff y M. Álvarez Martí-Aguilar, Identidades, culturas y territorios en la Andalucía prerromana, Sevilla-Málaga, 205-236.

Fishman, J. 1965: "Who speaks that language, to whom and when?", La Linguistique 1 (2), 67-88.

Fishman, J. 1967: "Bilingualism with and without diglossia; diglossia with and without bilingualism", Journal of Social Issues 23 (2), 29-38. https://doi.org/10.1111/j.1540-4560.1967.tb00573.x

Fishman, J. (ed.) 2014: Advances in the study of Societal Bilingualism, Den Haag, $2^{\text {a }}$ edición.

Galsterer, H. 1971: Untersuchungen zum römischen Städtewesen auf der Iberischen Halbinsel, Berlin.

García-Bellido, M. P. 1982: Las monedas de Cástulo con escritura indígena, Barcelona. 
García-Bellido, M. P. 1990: "Iconografía fenicio-púnica en moneda romano republicana de la Bética", Zephyrus 43, 371-383.

García-Bellido, M. P. 1993: "El proceso de monetización en el Levante y Sur hispánico durante la Segunda Guerra Púnica”, J. Untermann y F. Villar (eds.), Lengua y cultura en la Hispania prerromana. Actas del V Coloquio sobre Lenguas y Culturas Prerromanas de la Península Ibérica (Colonia, 25-28 de Noviembre de 1989), Salamanca, 317-348.

García-Bellido, M. P. 1995: "Moneda y territorio: la realidad y su imagen", Archivo Español de Arqueología 68, 131-147. https://doi.org/10.3989/aespa.1995.v68.402

Gasca, M. y Fletcher, D. 1989-1990: "Grafitos y letreros ibéricos de Alcañiz (Teruel)”, Kalathos 9-10, 135-146.

Goodman, M. 2005: "Coinage and identity: the Jewish evidence", C. Howgego, V. Heuchert y A. Burnett (eds.), Coinage and identity in the Roman provinces, Oxford, 163-166.

González, J. 1982: Inscripciones romanas de la provincia de Cádiz, Cádiz.

Graells, R. 2014: Mistophoroi ex Iberias : una aproximación al mercenariado hispano a partir de las evidencias arqueológicas (s. VI-IV a.C.), Venosa.

Grosjean, F. 1982: Life with two languages, Massachussets-London.

Hamers, J. F. y Blanc, M. 2000: Bilinguality and bilingualism, Cambridge, $2^{\mathrm{a}}$ edición.

Häussler, R. 2002: "Writing Latin: from resistance to assimilation. Language and society in N. Italy and S. Gaul", A. Cooley (ed.), Becoming Roman, Writing Latin, Literacy and Epigraphy in the Roman West, JRA Supplementary Series 48, Portsmouth, 61-76.

Häussler, R. 2013: Becoming Roman? Diverging identities and experiences in ancient Northwest Italy, London.

Herrera, J. 2015: “Cultura epigráfica y romanización en el ámbito ibérico meridional”, Palaeohispanica $15,57-86$.

Herrera, J. 2016: "La desaparición de las lenguas y las escrituras paleohispánicas en el sur peninsular", Antesteria 5, 153-163.

Hirt, A. M. 2014: "Beyond Greece and Rome: Foundation Myths on Tyrian Coinage in the Third Century AD", N. Mac Sweeney (ed.), Foundation Myths in Ancient Societies. Dialogues and Discourses, Philadelphia, 190-225

Howgego, C. 2005: "Coinage and identity in the Roman provinces", C. Howgego, V. Heuchert y A. Burnett (eds.), Coinage and identity in the Roman provinces, Oxford, 1-17.
Jiménez, A. 2014: "Punic after Punic times? The case of the so-called 'Libyphoenician' coins of southern Iberia”, J. C. Quinn y N. C. Vella (eds.), The Punic Mediterranean. Identities and identification from Phoenician settlement to Roman rule, Cambridge, 219-242.

Juan, J. 1988: Epigrafía Romana de Ebusus, Ibiza.

Keay, S. 1992: "The 'romanisation' of Turdetania”, Oxford Journal of Archaeology 11 (3), 275-315. https://doi.org/10.1111/j.1468-0092.1992. tb00272.x

Kerr, R. M. 2010: "Some thoughts on the origins of Libycor-Berber alphabet", H. Stroomer et alii (eds.), Études berbères V. Essais sur des variations dialectiales et autres articles. Actes $d u$ '5. Bayreuth-Frankfurt-Leidener Kolloquium zur Berberologie', Köln, 41-68.

Langslow, D. R. 2002: "Approaching bilingualism in corpus languages", J. N. Adams, M. Janse y S. Swain (eds.), Bilingualism in Ancient Societies, Oxford, 23-51. https://doi.org/10.1093/acprof:o so/9780199245062.003.0002

Lázaro, R. 1980: Inscripciones romanas de Almería, Almería.

Lee, S. I. 2012: Jesus and Gospel traditions in bilingual context. A study in the interdirectionality of language, Berlin-Boston.

Llorens, M. M. y Ripollès, P. P. 2002: "Las imágenes", en P. P. Ripollès y M. M. Llorens (eds.), Arse Saguntum. Historia monetaria de la ciudad y su territorio, Sagunto, 63-120.

López, M. D. y Ruiz, A. 1995: Nuevas inscripciones latinas del Museo de Cádiz, Cádiz.

López Castro, J. L. 1991: "El foedus de Gadir del 206 a. C.: una revisión”, Florentia Iliberritana 2, 269280.

López Castro, J. L. 1995: Hispania poena. Los fenicios en la Hispania romana, Barcelona.

López Castro, J. L. 2007: “The western phoenicians under the Roman republic: integration and persistence", P. van Dommelen y N. Terrenato (eds.), Articulating Local Cultures. Power and identity under the Expanding Roman Republic. JRA Supplementary Series 64, Portsmouth, 103125.

López Castro, J. L. y Mora, B. 2002: “Malaka y las ciudades fenicias en el Occidente mediterráneo, siglos VI a. C. - I d. C.", Mainake 24, 181-214.

Lykke, A. 2012: "The use of languages and scripts in ancient Jewish coinage. An aid in defining the role of the Jewish temple until its destruction in 70 CE", D. M. Jacobson y N. Kokkinos (eds.), Judaea and Rome in Coins 65 BC-135 CE, London, 27-50. 
Machuca, F. 2017: "La integración de las comunidades fenicias de la península Ibérica en el Imperio Romano. Un análisis poscolonial", F. Prados y F. Sala, F. (eds.), El oriente de Occidente. Fenicios y púnicos en el área ibérica, Alicante, 465-482.

Mastino, A. 1985: "Le relazioni tra Africa e Sardegna in età romana: inventario preliminare", A. Mastino (ed.), L'Africa Romana. Atti del II convegno di studio, 14-16 dicembre 1984, Sassari (Italia), Sassari, 27-91.

Mattingly, D. J. 2005: Tripolitania, London.

Mayorga, J. A., Escalante, M. M. y Cisneros, M. I. 2005: "Evolución urbana de la Málaga romana, desde sus inicios hasta el siglo III d. C.", Mainake 27, 141-168.

Melucci, A. 1995: The Process of Collective Identity, Philadelphia.

Metcalf, W. E. 1999: "Coins as primary evidence”, G. M. Paul y M. Ierardi (eds.), Roman coins and public life under the Empire. E. Togo Salmon Papers II, Ann Arbor, 1-17.

Millar, F. 1993: The Roman near East. 31 BC - AD 337, Cambridge-London.

Molina, F. 1986: "Almuñécar a la luz de los nuevos hallazgos fenicios", G. Del Olmo y M. E. Aubet (eds.), Los fenicios de la península Ibérica, Sabadell, 1, 193-216.

Mora, B. 2000: "Las fuentes de la iconografía monetal fenicio-púnica”, L. Callegarin y M. P. García-Bellido (eds.), Los cartagineses y la monetización del Mediterráneo Occidental, Anejos de Archivo Español de Arqueología XXII, 157-168.

Mora, B. 2004: "Notas sobre la escritura latina en la amonedación antigua de Hispania”, F. Chaves y F. J. García Fernández, (eds.), Moneta qua scripta. La moneda como soporte de escritura: actas del III Encuentro Peninsular de Numismática Antigua. Anejos de Archivo Español de Arqueología XXXIII, Madrid, 115-122.

Mora, B. 2005: "La moneda fenicio-púnica de Hispania en el siglo I a. C.", La moneda al final de la República: entre la tradició i la innovació, Barcelona, 51-72.

Mora, B. 2012: "Moneda e identidades en las amonedaciones de la Ulterior-Baetica: zonas nucleares y periferias", J. Santos y G. Cruz Andreotti (eds.), Romanización, fronteras y etnias en la Roma Antigua: el caso hispano, Vitoria, 735-771.

Mullen, A. 2012: "Introduction: multiple languages, multiple identities", A. Mullen y P. James (eds.), Multilingualism in the Graeco-Roman Worlds, Cambridge, 1-35.

Mùrcia, C. 2011: La llengua amaziga a l'antiguitat a partir de les fonts gregues i llatines, Barcelona.
Ortiz, E. 2012: "La evolución política de las ciudades de tradición fenicio-púnica bajo la dominación romana (II a. C. - I d. C.), B. Mora y G. Cruz (eds.), La etapa neopúnica en Hispania y el Mediterráneo centro occidental: identidades compartidas, Sevilla, 191-222.

Padilla, A. 2011: "Algunas cuestiones en torno a la elite de Carteia", Gerión 29 (1), 239-263. https:// doi.org/10.5209/rev_geri.2011.v29.n1.39056

Quesada, F. 1994: "Vías de contacto entre la Magna Grecia e Iberia: la cuestión del mercenariado", D. Vaquerizo (ed.), Arqueología de la Magna Grecia, Sicilia y la Península Ibérica, Córdoba, 191-246.

Quinn, J. C. 2003: "Roman Africa?", A. D. Merryweather y J. R. W. Prag (eds.), Romanization? Digressus Supplement 1, London, 7-34.

Quinn, J. C. 2010: “The reinvention of Lepcis”, XVII International Congress of Classical Archaeology, Roma 22-26 Sept. 2008. Bollettino di Archeologia On-line 1, Roma.

Quinn, J. C. y McCarthy, M. 2015: "Echos puniques: langue, culte, et gouvernement en Numidie hellénistique", D. Badi (ed.), Massinissa, au cour de la consécration d'un premier État numide, 167-198.

Ripollès, P. P. 1988: La ceca de Valentia, Valencia.

Ripollès, P. P. 2005a: "Las acuñaciones antiguas de la península Ibérica: dependencias e innovaciones", C. Alfaro Asins, C. Marcos Alonso y P. Otero Morán (eds.), XIII Congreso Internacional de $\mathrm{Nu}$ mismática, Madrid, 2003, Madrid, 187-208.

Ripollès, P. P. 2005b: "Coinage and identity in the Roman provinces: Spain”, C. Howgego, V. Heuchert y A. Burnett (eds.), Coinage and identity in the Roman provinces, Oxford, 79-93.

Ripollès, P. P. y Llorens, M. M. (eds.) 2002: ArseSaguntum. Historia monetaria de la ciudad y su territorio, Sagunto.

Robinson, M. 1997: "Phoenician inscriptions on the late Roman bronze coinage of Tyre. Part I. Coin depicting Pygmalion", NCirc 105 (7), 234-236.

Robinson, M. 1999: “Gordian III's bronze coinage of Tyre: a further specimen with Phoenician letters", NCirc 107 (2), 43.

Rochette, B. y Clackson, J. 2011: "Language Policies in the Roman Republic and Empire", J. Clackson (ed.), A Companion to Latin language, Oxford.

Roldán, L., Bendala, M., Blánquez, J. y Martínez, S. (eds.) 2006: Estudio histórico-arqueológico de la ciudad de Carteia (San Roque, Cádiz) 1994-1999. Vol. 1, Madrid.

Rutter, N. K. 2001: Historia Numorum. Italy, Cambridge.

Sánchez, M. L. 2004: "Municipalización y munificencia en Ebusus", Collection de l'Institut de Sciences 
et Techniques de l'Antiquité 3 (= Hommages à Monique Clavel-Lévêcque), Besançon, 326-335.

Scopacasa, R. 2015: Ancient Samnium. Settlement, culture and identity between History and Archaeology, Oxford.

Simkin, O. 2012: "Coins and language in ancient Sicily", O. Tribulato (ed.), Language and linguistic contact in Ancient Sicily, Cambridge, 162-187.

Stone, C. 2014: "History and Archaeology of Morgantina”, S. C. Stone (ed.), Morgantina Studies, Volume VI: The Hellenistic and Roman Fine Pottery, Princeton, 3-80.

Stylow, A. U. 2001: "Una aproximación a la Carmo romana a través su epigrafía. Nuevas aportaciones y revisión crítica”, A. Caballos (ed.), Carmona romana, Carmona, 95-106.

Swain, S. 1996: Hellenism and empire: language, classicism and power in the Greek world. AD 50 250, Oxford.

Tagliamonte, G. 1994: I figli di Marte: mobilità, mercenari e mercenariato italici in Magna Grecia e Sicilia, Roma.

Tataranni, F. 2005: "Il toro, la lupa e il guerriero: l'immagine marziale dei Sanniti nella monetazione degli insorti italici durante la Guerra Sociale (90-88 a. C.)", Athenaeum 93 (1), 291-304.

Tribulato, O. 2012: "Siculi bilingues? Latin in the inscriptions of early Roman Sicily", O. Tribulato (ed.), Language and language contact in ancient Sicily, Cambridge, 291-325.

Untermann, J. 1995: "La latinización de Hispania a través del documento monetal”, M. P. García-Bellido y R. M. Sobral Centeno (eds.), La moneda hispánica: ciudad y territorio. Actas del I Encuentro Peninsular de numismática antigua, Anejos de Archivo Español de Arqueología XIV, Madrid, 305-316.

Van Dommelen, P. 2001: "Punic persistence: colonialism and cultural identities in Roman Sardinia", R. Laurence y J. Berry (eds.), Cultural Identity in the Roman Empire, London-New York, 25-48.
Van Dommelen, P. 2007: "Beyond resistance: Roman power and local traditions in Punic Sardinia", P. Van Dommelen y N. Terrenato (eds.), Articulating local cultures: power and identity under the expanding Roman Republic, Portsmouth, 55-69.

Velaza, J. 2002: "Las inscripciones monetales", P. P. Ripollès y M. M. Llorens (eds.), Arse-Saguntum. Historia monetaria de la ciudad y su territorio, Sagunto, 121-148.

Vismara 1990: "Sopravvivenze puniche e persistenze indigene nel Nord Africa ed in Sardegna in età romana. Introduzione", A. Mastino (ed.), L'Africa romana: atti del 7. Convegno di studio, 15-17 dicembre 1989, Sassari (Italia), Sassari, 39-47.

Willi, A. 2008: Sikelismos: Sprache, Literatur und Gesellschaft im griechischen Sizilien (8.-5. Jh. v. Chr.), Basel.

Williamson, G. 2005: "Aspects of identity", C. Howgego, V. Heuchert y A. Burnett (eds.), Coinage and identity in the Roman provinces, Oxford, 19-27.

Wulff, F. 2009: “¿Por qué las identidades hoy?”, F. Wulff y M. Álvarez (eds.), Identidades, culturas y territorios en la Andalucía prerromana, SevillaMálaga, 11-50.

Wulff, F. 2011: "Hablando de identidades. Reflexiones historiográficas sobre Italia entre la república y el imperio", A. Caballos y S. Lefebvre (eds.), Roma generadora de identidades. La experiencia hispana, Madrid, 21-37.

Zamora, J. A. 2013: "Novedades de epigrafía feniciopúnica en la península Ibérica y sus aledaños", X. Ballester, F. Beltrán, F. J. Fernández Nieto, C. Jordán y J. Siles (eds.), Acta Palaeohispanica XI. Actas del XI Coloquio internacional de Lenguas y Culturas Prerromanas de la Península Ibérica [= PalHisp 13], Zaragoza, 359-384.

Recibido: 06-11-2017

Aceptado: 04-05-2018 